The BMJ

Cite this as: BMJ 2021;373:n1139 http://dx.doi.org/10.1136/bmj.n1139 Published: 04 May 2021

\title{
GPs are at "breaking point" and in need of respite, leaders warn
}

\section{Gareth lacobucci}

General practices are "reaching breaking point" because of the "intense" workload pressure facing doctors and staff, the country's most senior GP leaders have warned.

The warning came as new figures from NHS Digital showed that practices in England delivered almost five million more appointments in March 2021 than the month before and nearly three million more than in March 2019. ${ }^{1}$

Richard Vautrey, chair of the BMA General Practitioners Committee, said that the figures underlined the huge efforts practices were going to and the workload pressure on staff. He said, "GPs and their teams are consistently telling us they're busier now than they have ever been, and this data-which does not include a large proportion of the vaccine programme undertaken by practices, nor a vast amount of other daily tasks-backs this up."

The figures came as the BMA's latest tracker survey of GPs and hospital doctors, published this week, ${ }^{2}$ found that thousands were considering leaving the NHS in the next year because of exhaustion, stress, and burnout caused by working without respite during the pandemic. Half the respondents (2099 of 4240) said they planned to work fewer hours in the next 12 months, 25\% (1065) said they were "more likely" to take a career break, 21\% (882) said they were considering leaving the NHS for another career, and 32\% (1352) were considering early retirement.

Vautrey said that the survey results should serve as a "wake-up call" to the government. "Our calls must be listened to and our workforce truly valued," he said. "This means giving GPs the respite they need and access to proper breaks to ensure no more feel forced to leave a career they've worked so hard to achieve."

NHS Digital's data show that general practices delivered an estimated 28.4 million appointments in March 2021, up from 23.5 million in February and 25.6 million in March 2019. The latest data included some covid vaccinations (1.24 million in March), but most vaccination appointments were logged in different systems.

This March 15.9 million appointments (56\%) were face to face, 11.4 million (40\%) were telephone consultations, and the rest by other means such as video consultations or home visits.

Commenting on the appointment figures, Martin Marshall, chair of the Royal College of General Practitioners, said, "General practice was facing intense workforce and workload pressures. The pandemic has only exacerbated these pressures. Good progress has been made to encourage medical students to choose general practice, but we also need to see comprehensive plans to keep existing and experienced GPs in the workforce, protecting them from burning out by addressing 'undoable' workloads."

Vautrey said the data also contradicted false perceptions that practices were seeing few patients. "This narrative, categorically proven wrong by [the] data, is extremely damaging at a time when morale is already reaching rock bottom and many GPs, practice managers, and others in the practice workforce are reaching breaking point," he said.

Last week the Ivy Grove Surgery in Derbyshire provided an example of the strain facing some practices in a 16 page open letter to its patients about the huge demand it was facing and the resulting risk of staff burnout. ${ }^{3}$ The surgery said it would be reducing its use of the video consultation tool eConsult, as it had seen a doubling of demand over recent months, with some patients submitting several requests a day.

In a statement the practice told The BMJ, "We are aware of the stir our letter has caused but have also been overwhelmed by the kind feedback from our own patients, and the many encouraging messages of support we have received from GP surgeries all around the country. We therefore know that many of our GP colleagues are experiencing the same issues, but they may be fearful of articulating what is happening.

"We feel that open and honest debate about demand and workload in general practice is vital. If this letter goes even a little way towards sparking some much needed discussion then it will have been a good thing."

Commenting on the stresses facing practices, Vautrey added, "The unseen reality is that those pre-pandemic, once full, reception areas are now overflowing virtual waiting rooms, with the GP team working non-stop throughout the week. It can therefore be challenging for practices to sensitively communicate just how busy they are to patients, while ensuring that those with health needs who do need to contact their practice continue to do so.

"It's therefore vital that NHS England and the government are honest with the public about the pressures on general practice and GP staff, provide clear public health guidance about what services are available across the NHS and when it is appropriate to use them, and also plan properly for the future, with increased investment to improve practice premises that can safely support social distancing."

NHS Digital. Appointments in general Practice March 2021: official statistics, experimental statistics. Apr 2021. https://digital.nhs.uk/data-and-information/publications/statistical/appointments-in-general-practice/march-2021. BMA. BMA survey covid-19 tracker survey snapshot April 2021. https://www.bma.org.uk/media/4055/bma-survey-april-2021-uk-overallsnapshot.pdf. 
3 Surgery IG. An open letter to our patients about demand. 26 Apr 2021. https://www.ivygrove.org.uk/downloads/Open_Letter_to_our_Patients_about_Demand.pdf. 